\title{
Computational analysis of a cross flow turbine performance
}

\author{
Vanessa Ruiz Gómez ${ }^{1 *}$, Edison A. Palacio Higuita ${ }^{1}$, and Aldo Germán Benavides Morán ${ }^{1}$ \\ ${ }^{1}$ Mechanical Engineering Department, Facultad de Minas, Universidad Nacional de Colombia, sede Medellín, Colombia
}

\begin{abstract}
In the electrical energy generation context in Colombia, the water resources represent the $64 \%$ of the potential generated according to UPME in the 2015 year; becoming into a solution to the growing energy demand and to the supply of energy in non-interconnected zones. The cross-flow turbines as Michell-Banki type, become an efficient and economically attractive choice. This paper shows the fluiddynamic performance of a laboratory's model turbine under several operating conditions. The development of this analysis is supported by the results of experimental tests, uses the computational fluid dynamics as a tool for modelling, estimate, and analyse the turbine behaviour under different operating conditions, with ANSYS-Fluent software; the computational model considers the most important geometric aspects of the turbine and the opening percentage effect of the guide blade. The water flow through the rotor is approach through a turbulence model as $\kappa-\varepsilon$ type. The numerical study results agree satisfactorily with the turbine performance observed in the laboratory.
\end{abstract}

\section{Introduction}

In the electrical energy generation context in Colombia, the water resources are highly exploited, these provides about the $64 \%$ of potential generated for national interconnected system [5], besides represents a solution to growing energetic demand and its supply in noninterconnected zones.

Because of this is necessary to implement means that make up for the demand in an economical and efficient way, Michell - Banki turbine has been an alternative used for it, and this paper shows the performance evaluation for a laboratory model under different operating conditions.

Functioning of this turbomachinery type lies in move rotor due to blades interaction with fluid flow and pressure difference generated here, the fluid gets in by a nozzle where is valve that regulates the flow according to the angular velocity needed by the electric generator, it is a coupled to the rotor shaft.

Computational fluid dynamics has been used to determine the behaviour of different models [4,6,7], propose enhancements in design according to most influential parameters in its performance, like dimensions, number of blades and turbine's valve opening percentage, and find the optimal conditions for the fluid in the system. Development of this paper is based in previous researching results and it focuses on analyse, under different states, the model operating conditions, figure 1 , which main features are included in table 1, where $\alpha$ is the angle between the circumferences that describes blades trajectory, and $\lambda$ angle defines the opening circumference arc towards the rotor.
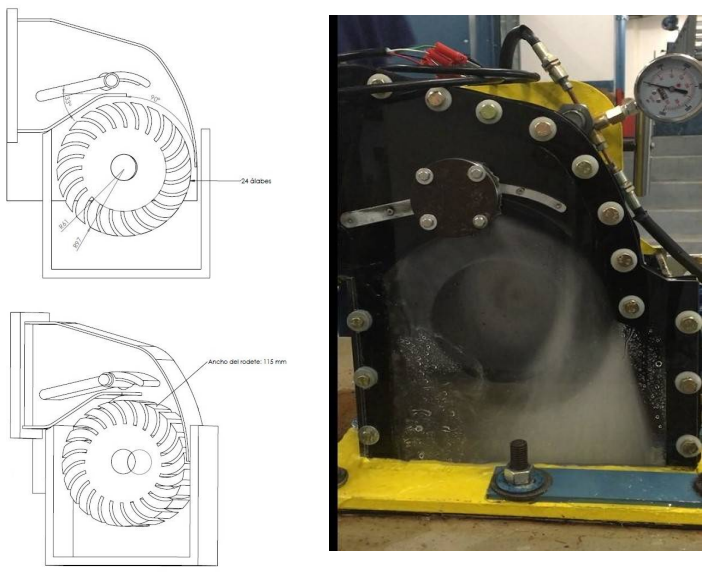

Fig. 1. CAD (left) y turbine model (right).

Table 1. Model geometric features.

\begin{tabular}{|l|c|c|c|}
\hline Rotor internal diameter & $0,122 \mathrm{~m}$ & $\boldsymbol{\kappa}$ & $33^{\circ}$ \\
\hline Rotor external diameter & $0,194 \mathrm{~m}$ & $\lambda$ & $90^{\circ}$ \\
\hline Blades number & 24 & Rotor width & $0,115 \mathrm{~m}$ \\
\hline
\end{tabular}

\section{Methods}

Previous developed analyzes around this turbine types [3], allow to compare and establish the most important geometrical parameters in the system, like the nozzle curvature, profile and number of blades, opening valve position, rotor size, well, affect directly to fluid behavior and relate operating features, like flow, flow direction and smoothness, and distribution of pressure and velocity.

Obtained experimental results, as well as advices from previous studies, offer reference points to prove

\footnotetext{
* Corresponding author: varuizgo@unal.edu.co
} 
computational simulations completely and to characterize turbine functioning, comparing pressure drop through this, with the available energy that is in the flow initially. For that, equation (1) is used, where $\mathrm{T}$ is the rotor torque at a certain angular velocity, $\omega, \mathrm{Q}$ is the flow, $\rho$ is density, $g$ is gravity acceleration and $\mathrm{H}$ is hydraulic head; to know the efficiency some measurements were made at different operating conditions.

$$
\eta_{\mathrm{t}}=\frac{T \cdot \omega}{\rho g Q H}
$$

With the objective to model the flow behavior in the turbine in a computational and suitable way, turbulence model $\kappa-\varepsilon$ realizable is used, this model is based on Navier-Stokes equations for mean velocity field (RANS), it looks for solve Reynolds stress under Eddy's viscosity linear model or turbulent viscosity. This model includes two transport equations more, one of this for turbulent kinetic energy, $\kappa$, and other for its dissipation rate, $\varepsilon$. This model presents a realizability constrain that imposes a limit on turbulent viscosity. This is a suitable model for flows with high curvature in its streamlines or flow in rotation.

Now RANS (2) and transport equations (3) y (4) are presented, where $\mathrm{p}$ is fluid density, it is taken as constant property, is mean velocity, is fluid velocity fluctuation and term represents Reynolds stress.

$$
\rho\left[\frac{\partial U_{i}}{\partial t}+U_{j} \frac{\partial u_{i}}{\partial x_{j}}\right]=-\frac{\partial p}{\partial x_{i}}+\frac{\partial}{\partial x_{j}}\left[T_{i j}-\rho \overline{u_{1} u_{j}}\right]
$$

In equation (2) the first term to the left represents mean velocity local change rate, second term is convective acceleration, first term to the right is pressure gradient in flow direction, next term represents viscous stress gradient due to fluid properties and, last is a term known as Reynolds stress that represents momentum transfer due to flow fluctuations.

$$
\begin{gathered}
\frac{\partial k}{\partial t}+v_{j} \frac{\partial k}{\partial x_{j}}=\frac{\partial}{\partial x_{j}}\left[\left(v+\frac{v_{t}}{\sigma_{k}}\right) \frac{\partial k}{\partial x_{j}}\right]+\mathcal{P}^{k}-\epsilon \\
\frac{\partial \xi}{\partial t}+U_{j} \frac{\partial \xi}{\partial x_{j}}=\frac{\partial}{\partial x_{j}}\left[\left(v+\frac{v_{t}}{\sigma_{i}}\right) \frac{\partial \xi}{\partial x_{j}}\right]+\frac{\xi}{k}\left(c_{\mathrm{z} 1} \mathcal{P}^{k}-c_{21} \varepsilon\right)
\end{gathered}
$$

Transport equations right side (3) and (4) for $\kappa-\varepsilon$ respectively, contain corresponding advective terms, local change rate, in mentioned order for each variable, turbulent kinetic energy and its dissipation rate. Left side of both equations involves transport, production and dissipation terms, respectively.

\section{Results}

Fluid behavior was analyzed inside turbine in steady and transient state, model was simplified by a bidimensional geometry and different operating conditions were considerate, moreover a measurements set were made on laboratory model to compare results and know turbine performance.

\subsection{Steady state results}

Three different angular velocities were considered in steady state: 200, 220, 250 RPM for each flow supposed: 50 and $91 \mathrm{~L} / \mathrm{seg}$. In the last case efficiency drastically drops due to a high flow and low angular velocities for the rotor while at $50 \mathrm{~L} / \mathrm{seg}$ flow, turbine can work with low angular velocities and still gets good efficiencies at certain pressure drops, in fact, is found that better turbine efficiency is $84 \%$, for evaluated cases, at $50 \mathrm{~L} / \mathrm{seg}$ and pressure drop of $70 \mathrm{kPa}$. Some results are reported in table 2 .

Table 2. Numerical results for $50 \mathrm{~L} / \mathrm{s}$ and some angular velocities.

\begin{tabular}{|c|c|c|c|}
\hline $\begin{array}{c}\text { Flow } \\
{[\mathbf{L} / \mathbf{s}]}\end{array}$ & $\begin{array}{c}\text { angular } \\
\text { velocity } \\
{[\mathbf{r p m}]}\end{array}$ & Efficiency & $\begin{array}{c}\text { Pressure } \\
\text { drop } \\
{[\mathbf{k P a}]}\end{array}$ \\
\hline 50 & 250 & $84 \%$ & 70 \\
\hline 50 & 220 & $47 \%$ & 68 \\
\hline 50 & 200 & $35 \%$ & 65 \\
\hline
\end{tabular}

Figure 2 shows that fluid velocity decreases just a bit when it hits a blade for first time, and nozzle opening arc allows to fluid get it to the rotor through six blades at the same time. Small space at the right side between turbine wall and rotor, causes some acceleration in outgoing fluid, while in practice it was observed that there are some recirculation at the left side.

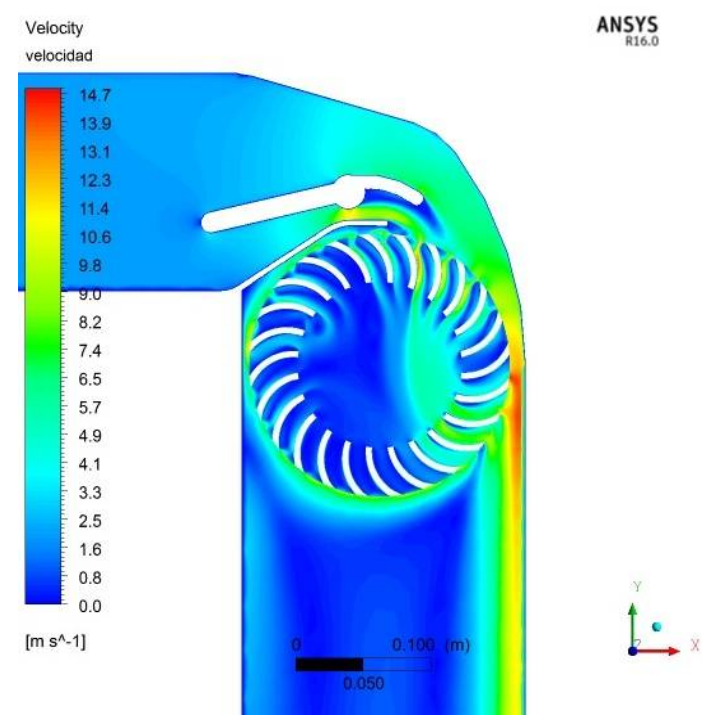

Fig. 2. Velocity contours at $50 \mathrm{~L} / \mathrm{s}$ and $250 \mathrm{rpm}$.

Turbulent kinetic energy gets big magnitudes in flow zones that are below director blade bearing surface, and it is significantly biggest between blades zones at rotor entrance, like figure 3 shows. It could infer that in this zones turbulence is generated in the flow due to high velocity gradients, in other flow zones turbulent kinetic energy has a small magnitude and is uniform because streamlines don't have big fluctuations. 
Table 3. Numerical results in transient state ad different operating condition.

\begin{tabular}{|c|c|c|c|c|}
\hline $\begin{array}{c}\text { Flow } \\
{[\mathbf{L} / \mathbf{s}]}\end{array}$ & $\begin{array}{c}\text { Angular } \\
\text { velocity } \\
{[\mathbf{r p m}]}\end{array}$ & $\begin{array}{c}\text { Pressure } \\
\mathbf{d r o p} \\
{[\mathbf{k P a}]}\end{array}$ & $\begin{array}{c}\text { Power } \\
{[\mathbf{k W}]}\end{array}$ & Efficiency \\
\hline 28 & 600 & 31,5 & 1,2 & $30 \%$ \\
\hline 32 & 956 & 47 & 1,5 & $44 \%$ \\
\hline 33 & 510 & 35 & 1,8 & $33 \%$ \\
\hline 40 & 1250 & 76 & 3,3 & $71 \%$ \\
\hline 43 & 1329 & 82 & 4 & $76 \%$ \\
\hline
\end{tabular}

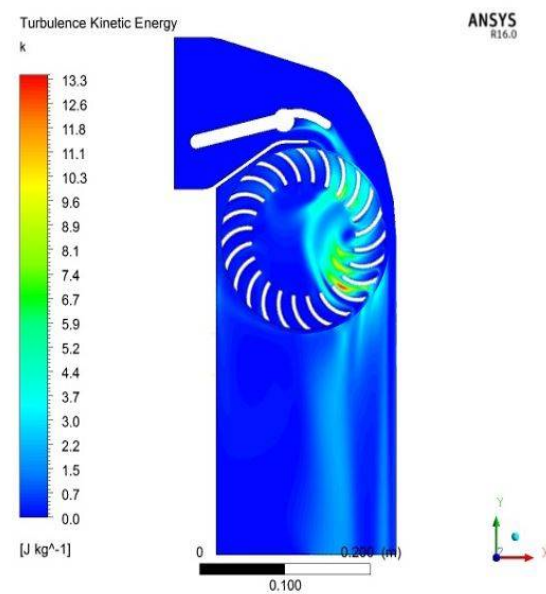

Fig. 3. Turbulent kinetic energy contours at $50 \mathrm{~L} / \mathrm{s}$ and $250 \mathrm{rpm}$.

\subsection{Transient state results}

To determine turbomachinery behavior is important to include time in developed analysis to get more accurate results, because of this, turbulence model $\kappa-\varepsilon$ realizable, is used in a transient state. In table 3, different flows and angular velocities values are summarized. Until a certain angular velocity, increasing flow takes to increasing pressure drop and efficiency, but in other hand, when angular velocity is too low for determined flow, generated power will be smaller, and thus, turbine efficiency too. It is pointing out that turbine is working below its optimal operating point.

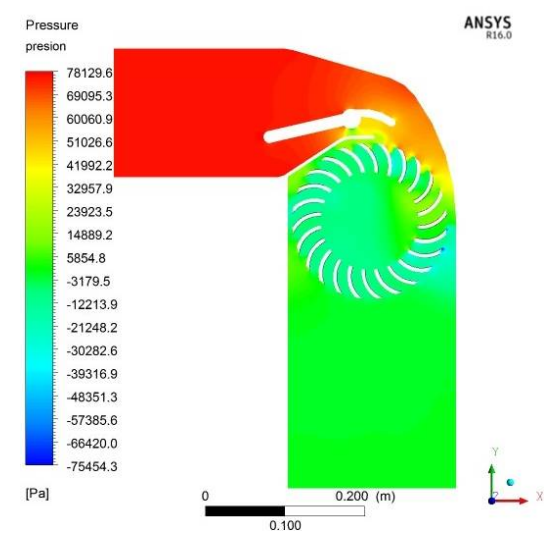

Fig. 4. Pressure contours at $40 \mathrm{~L} / \mathrm{s}$ and $1250 \mathrm{rpm}$.

Given that Michell - Banki turbine is define as a reaction turbine, there is a significantly pressure drop through rotor as can see in figure 4 . Worth to advise that energetic losses from turbine entrance to crossing to rotor, are small, valve opening percentage, at turbine entrance, make that fluid pressure decreases, in a small zone there. While the fluid that gets to go over the valve, arrives with a bigger pressure compared with the flow below the valve.

Moreover, it can see with colors scale help, how pressure drops through rotor and after first fluid path through blades. In other hand, there is a pressure difference between blade faces to propel its movement, this difference can be seen in external blades tip.

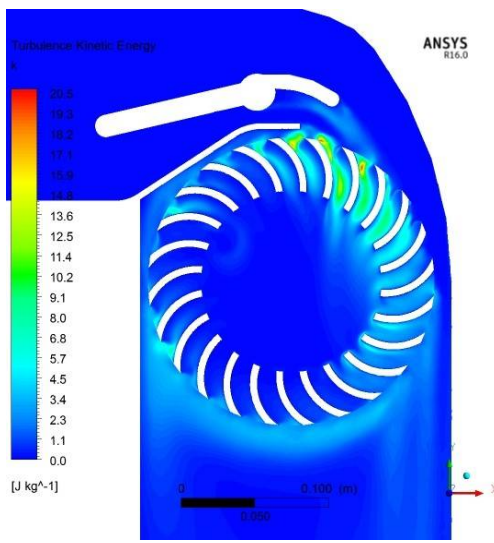

Fig. 5. Turbulent kinetic energy contours at $40 \mathrm{~L} / \mathrm{s}$ and 1250 rpm.

Comparing turbulent kinetic energy contour in steady and transient state, we can see at first case energy dissipation along streamline through rotor, while in transient case dissipation occurs intensity around blades, like figure 5 shows. A possible cause for this, is increase in viscous effects with rotor movement.

After pass by the valve opening that regulates flow through rotor, fluid increases its velocity significantly and keeps high value when cross rotor and finally, increases again by its second crossing through blades, as can be seen in figure 6 , in this way, energy is pulled out from fluid in two different points.

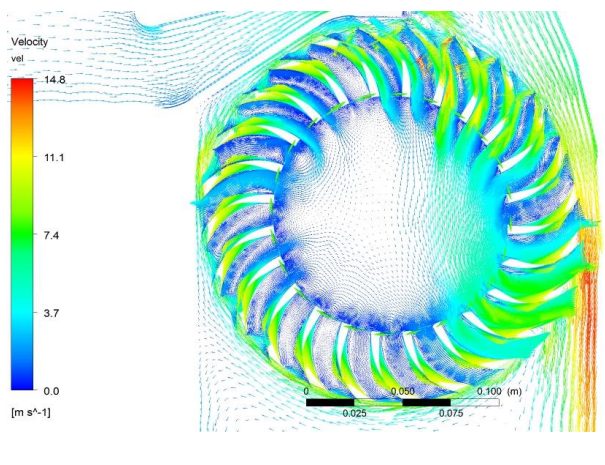

ANSYS

Fig. 6. Velocity vectors at $40 \mathrm{~L} / \mathrm{s}$ and $1250 \mathrm{rpm}$.

\subsection{Experimental results}

Aiming to characterize real turbine behavior at different opening valve percentage, flow, pressure and angular velocity measurements were carried out, applying four different force values to rotor through a pneumatic brake, 
like are summarized en table 4. Finding that at more braking force, more flow is necessary to make up for required power by electric generator shaft. At the same time there is a pressure decrease upstream, making to decrease turbine efficiency, this behavior trend is shown in graph 7.

Table 4. Model laboratory behavior for different positions of opening valve.

\begin{tabular}{|c|c|c|c|}
\hline $\begin{array}{c}\text { Valve } \\
\text { opening }\end{array}$ & $\begin{array}{c}\text { Pressure drop } \\
{[\mathbf{k P a}]}\end{array}$ & $\begin{array}{c}\text { Brake force } \\
{[\mathbf{N}]}\end{array}$ & Efficiency \\
\hline \multirow{4}{*}{ Totally open } & 54,4 & 0 & $51 \%$ \\
\cline { 2 - 4 } & 53,1 & 8,9 & $49 \%$ \\
\cline { 2 - 4 } & 52,4 & 13,4 & $49 \%$ \\
\cline { 2 - 4 } & 49,6 & 26,7 & $46 \%$ \\
\hline \multirow{4}{*}{ Open 3/4 } & 48,2 & 84,6 & $45 \%$ \\
\cline { 2 - 4 } & 58,6 & 0 & $54 \%$ \\
\cline { 2 - 4 } & 57,9 & 4,4 & $54 \%$ \\
\cline { 2 - 4 } & 57,2 & 8,9 & $53 \%$ \\
\hline \multirow{5}{*}{ Open 1/2 } & 56,5 & 17,8 & $53 \%$ \\
\cline { 2 - 4 } & 48,2 & 66,8 & $45 \%$ \\
\cline { 2 - 4 } & 63,4 & 0 & $59 \%$ \\
\cline { 2 - 4 } & 62,7 & 13,4 & $58 \%$ \\
\cline { 2 - 4 } & 61,3 & 17,8 & $57 \%$ \\
\hline
\end{tabular}

A trend observed as in numerical as in experimental result is, efficiency increases proportionally to flow, for studied values, moreover, is found that efficiency is smaller for experimental data than for numerical, for the same flow, as can be seen in figure 8. This is due to nonaccurate measurements, but in practice energetic losses in flow are bigger in experimental tests than in numerical simulations.

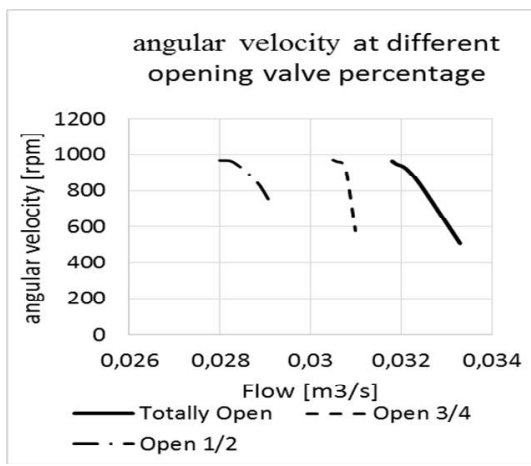

Fig. 7. Experimental results for angular velocity against flow for different entrance valve openings.

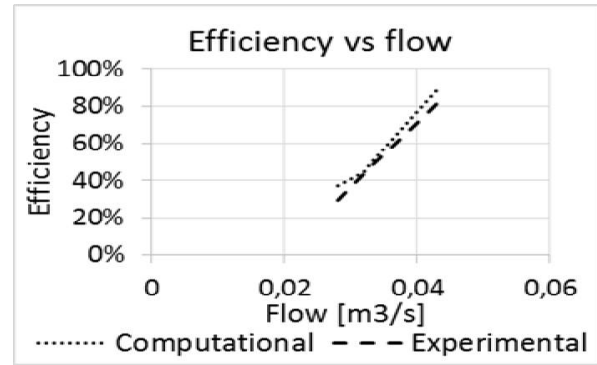

Fig. 8. Efficiency for experimental and computational results.

\section{Conclusions}

Michell-Banki turbine has a simple and economical design, moreover it can reach high efficiencies since it operates under suitable conditions, like was found in performed simulations, in this case maximum efficiency was $84 \%$ for $50 \mathrm{~L} / \mathrm{s}, 250 \mathrm{rpm}$ y $9 \mathrm{~m}$ of hydraulic head, like operating conditions; this make interesting to go in depth in studies around this model and implement them in electric energy generation sector to make the most of water resources that are close to non-interconnected zones.

Computational methods in the study of this turbines type allows to know model functioning and performance, under different operating conditions, which allows to identify improvement points on hydrodynamic and structural design and allows to simulate conditions that in practice are no easy to achieve, and although is possibly get very accurate results, it has high effort, time and cost computational.

Simulations in steady state were made under the supposition that the flow keeps fixed while angular velocity changes, to know what the effects could be of reach certain velocity in flow but, is known that in experimental case angular velocity can't change without flow changes too.

In velocity contours observed for different simulations settings, flow is affected by area reduction due to a small space between turbine casing and rotor, increasing its velocity, allowing a possible appearance for drag force in blades face that is in contact with flow that doesn't cross the rotor. Furthermore, in velocity contours it can be seen that in transient state is possible corroborate wall effect on flow, in other hand, in practice was seen that this zone is highly susceptible to flow recirculation and air bubble stack, so it is recommended enlarge this width and the walls towards discharge.

Although, experimental results serves like a reference point to compare computational results and establish a trend in turbine behavior, these aren't determining enough so, there are several effects that takes part negatively on reliability and accuracy, like measurement instrument calibration, leaks in system of tubes upstream to turbine, flow losses that are not in contact with rotor, and flow recirculation present by geometric features on turbine discharge position.

Is necessary experimental data measurement and analysis for different turbine operating conditions, make graphs and curves that characterize its performance, to compare with numerical results. Computational fluid dynamics results are a close relationship with experimental data trend, nevertheless results are a little different, no more than $15 \%$, due to all events without considering in simulations as flow irreversibleness and mistakes in measurements.

\section{References}

1. Gómez et al., La turbina Mochell-Banki y su presencia en Colombia (Avances en recursos hidráulicos, 2008) 
2. Paris et al., Construction and performance evaluation of Michell-Banki turbine prototype (2013)

3. Sammartano et al., Banki-Michell optimal design by computational fluid dynamics testing and hydrodynamic analysis (2013)

4. Sammartano et al., Experimental study of cross-flow micro-turbine for aqueduct energy recovery (2014)

5. UPME, Atlas potencial hidroenergético de Colombia (pp. 25-36, 2015)

6. Choi et al., Performance improvement of a cross-flow hydro turbine by air layer effect (2010)

7. Velasquez et al., Análisis de la influencia del porcntaje de apertura del álabe director sobre la potencia hidráilica de un picogenerador de flujo cruzado mediante un estudio númerico en software CFD (2013) 